\title{
Effects of Different Irrigation Amounts and Vermiculite Laying Modes on Poinsettia Water Consumption Characteristics and Water Use
}

\author{
Jie Li ${ }^{\mathrm{a}}$, Zhen-zhong Wu, Qi-jian Wang, Wei-bing Jia,Qi-liang Yang* ${ }^{*}{ }^{*}$ \\ Kunming University of Science and Technology, Yu Nan, Kunming 650500, China \\ a929631470@qq.com, byangqilianglovena@163.com.
}

\begin{abstract}
Keywords: Poinsettia, Irrigation, Vermiculite laying mode, Water consumption characteristics, Irrigation water use efficiency, Ornamental

Abstract.Two irrigation treatments (W1,total irrigation amount was12L.W2,total irrigation amount was $6 \mathrm{~L}$ ) and three vermiculite laying methods ( $\mathrm{Z} 0$, no vermiculite. $\mathrm{Z2}$, vermiculite was laid on the surface of the pot.Z2, vermiculite was laid in the bottom of the pot) were designed in the trial. The results showed that, the number and percentage of red leaves significantly decreased by $27.03 \%, 16.00 \%$ in $\mathrm{Z} 2$ treatment than $\mathrm{Z} 0$ when irrigation amount was $\mathrm{W} 1$, respectively. The number and percentage of red leaves respectively increased by $6.49 \%, 0.60 \%$ in $\mathrm{Z} 2$ treatment as compared to Z1 when irrigation amount was W2.Diurnal variation of evapotranspiration and transpiration of poinsettia showed a single peak curve, and the maximum were all occurred at the period of 14:00-16:00.The mass of dry matter (roots, stems) and the number of red leaves had a slight fall (no obvious difference) on the premise of saving 50\% irrigation amount in W2Z2 treatment than W1Z0,the total dry mass and evapotranspiration were all evidently decreased,while irrigation water use efficiency was significantly uplifted by $72.36 \%$.Therefore,W2Z2 treatment was the optimal combination mode which was not affected appreciation of the plants and meanwhile conducive to uplift for irrigation water use efficiency of potted poinsettia under the condition of the trial.
\end{abstract}

\section{Introduction}

Yunnan is a large flower production province in China. Severe impact has been exerted to the development of flower industry in the region due to the influence of global climate changes, increasingly aggravated seasonal drought which becoming a frequent and concurrent trend, recently. At present, the extensive water management for flower production in the region and waste of water resources was especially prominent. Therefore, high efficient water use in flower industry is one important aspect in relieving the tense situation of water use in the region. Poinsettia, one of the major flower varieties for the main festivals in China[1], and potted flower production is the main form[2]. Now, the studies of poinsettia at home and abroad mainly include, Liu et al. predicted the growth and quality formation of poinsettia by using Auxiliary heat than[3], Snipen et al. found two main factors which affect the development of poinsettia (average daily temperature and average daily artificial light intensity) and established the model of forecasting poinsettia from short-day treatment to the development of single bract, flowering in the experiment[4], Kirsten et al. studied the influence of nitrogen element on calcium distribution and dry matter of poinsettia[5], $\mathrm{Xu}$ et al. observed the growth of poinsettia with different training methods and concluded that the flower under the processing of four lateral branch in season of autumn and winter gained all best indexes[6], Song et al. performed the shorter processing for poinsettia and concluded that to ensure the appreciation of poinsettia, shorter processing need to continue to poinsettia budding[7], Wei et al. studied the tissue culture of poinsettia which include, from bud induction media, proliferation medium and rooting medium[8], Wu et al. studied the prevention and control of plant diseases and insect pests of poinsettia[9]. Poinsettia is an ornamental plant, the more red leaves, the more appreciation, domestic scholars studied the effect of environment, light quality and high temperature on poinsettia[10-12].

More researches focused on growth model of poinsettia and effect of different environment on the plant growth as mentioned above. However, the study on poinsettia water consumption characteristics and water use efficiency has not been reported at present in China. Of this study was carried out by the potted poinsettia with different irrigation amounts and vermiculite laying modes, 
and later measured and calculated the transpiration and evapotranspiration of poinsettia, the number and percentage of red leaves, the mass of dry matters in root, stem, leaf, whole plant and irrigation water use efficiency, etc. Growth, characteristics of water evapotranspiration and consumption as well as irrigation water use efficiency of the poinsettia was probed under the differed irrigation amounts and vermiculite laying modes, the result will provide reference for water-saving efficiency planting patterns of potted poinsettia.

\section{Material and method}

\subsection{Experimental zone profiles and materials}

The test was performed in February to June in 2013 in greenhouse of faculty of modern agricultural engineering in Kunming University of science and technology, the greenhouse is located in E102 '8', $\mathrm{N} 25^{\circ} 1^{\prime}$, indoor temperature and humidity were respectively controlled in the range of 18 to $25{ }^{\circ} \mathrm{C}$ and 30 50\%. Two-year poinsettia potted flowers were bought from Dounan international flower market in Chenggong county of Kunming, the average plant height was $20 \mathrm{~cm}$, crown diameter of 30 $\mathrm{cm}, 60$ poinsettia flowers with the uniform growth were selected from 1000 flowers and then transplanted into plastic pots $(30 \mathrm{~cm}$ in diameter at the top edge, $22.5 \mathrm{~cm}$ in diameter at the bottom, and $30 \mathrm{~cm}$ in depth), five holes (1 $\mathrm{cm}$ in diameter) were evenly distributed at the bottom to provide better aeration(one is in center ). One poinsettia was transplanted into each pot after that was filled with soil completely mixed by the same quantity of humus and turfy soil.

\subsection{Experimental design}

After the flowers were grown in pots for $20 \mathrm{~d}, 18$ pots with the uniform growth were selected from 60 pots for treatment, the test designed three vermiculite laying methods ( $\mathrm{Z} 0$, no vermiculite. $\mathrm{Z} 1$, vermiculite was laid on the surface of substrate. $\mathrm{Z} 2$, vermiculite was laid in the bottom of the pot), $0.1 \mathrm{~kg}$ vermiculite was used for each pot in groups of vermiculite processing, extra $0.1 \mathrm{~kg}$ soil (humus and lime soil were all $0.05 \mathrm{~kg}$ ) was added to the pots in the control to identical weight for all pots. Two irrigation amounts (W1, total irrigation amount was 12L, irrigation frequency was 3 days, total irrigation times was 24 during the test, each time 0.5L.W2, total irrigation amount was 6L, irrigation frequency was 6 days, total irrigation times was 12 during the test, each time 0.5L.), the experimental yielded 6 treatments and each treatment replicated three times, totally 18 pots. In order to avoid systematic error due to the possible differences in environmental condition, the position of the pots was randomly changed every 3 days, the experimental period was $91 \mathrm{~d}$ and other conditions were consistent.

\subsection{Measurements}

1) leaf number and mass of dry matter, poinsettia was harvested on June 1, 2013 and each plant was divided into three parts of root, stem and leaf, the number of red and total leaves of poinsettia were obtained by manual counting, some soil particles adhered to roots were rinsed clean with tap water, each organ was firstly dried in oven at $105{ }^{\circ} \mathrm{C}$ for $30 \mathrm{~min}$ and then dried at $80{ }^{\circ} \mathrm{C}$ to constant weight, the mass of dry matter for each part was measured via electronic balance with accuracy of $0.01 \mathrm{~g}$.

2) Determination of evapotranspiration and transpiration, the measurement of evapotranspiration and transpiration for each poinsettia was conducted by weighing method at an interval of $24 \mathrm{~d}$ from March 12, 13. The upper of flower pots was covered with back plastic bag and sealed the around of the flowerpot and plant stem with tape the night before the measurement of transpiration.

3) The calculation of irrigation water use efficiency, irrigation water use efficiency $\left(\mathrm{WUE}_{\mathrm{I}}\right)=$ total dry mass/total irrigation amount.

\subsection{Data analysis and processing method}

Using Microsoft excel 2003 software for data processing and origin8.5 for mapping, methods of one-way ANOVA and Duncan in SAS software $(\mathrm{P}=0.05)$ were performed for data analysis of variance and multiple comparisons. 


\section{Results and analysis}

2.1 Effect of different irrigation amounts and vermiculite laying way on the number of red leaves of poinsettia

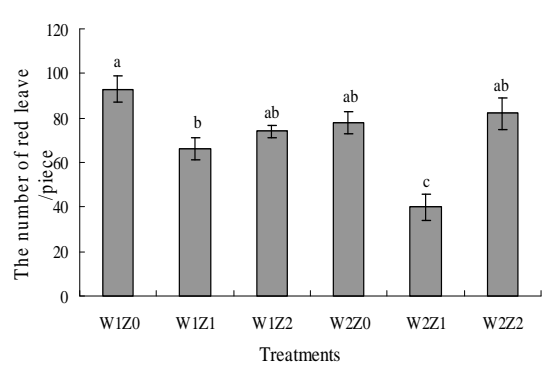

a

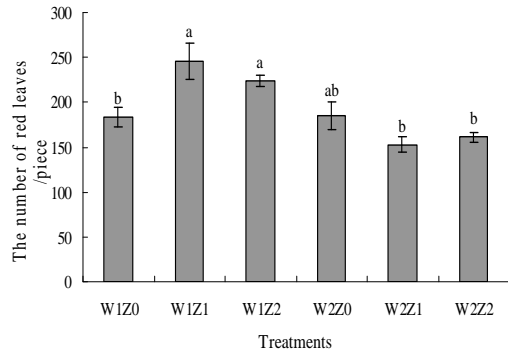

b

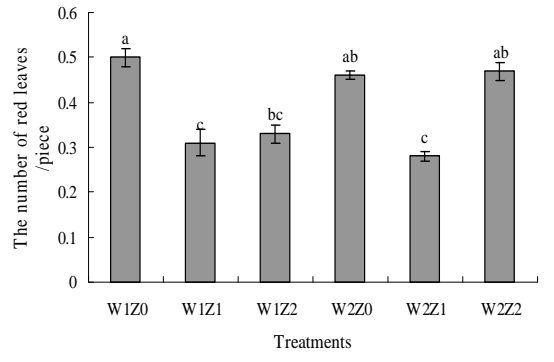

C

Fig.1 Effects of different treatments on leaf number of Poinsettia.

The number of poinsettia leaves as shown in Fig. 1, significant analysis results showed that effect was not significant $(\mathrm{P}>0.05)$ of different irrigation and vermiculite treatments as well as their interaction on total leaf number of poinsettia (Fig. 1b), while the influence of different irrigation and vermiculite treatments on the number and percentage of red leaves were all achieved significant levels $(\mathrm{P}<0.05)$ (showed in Fig. 1a, Fig. 1b, respectively). The number and percentage of red leaves of poinsettia in treatments of W1Z0 and W2Z2 were superior to the other treatments. The number and percentage of red leaves in W2 were respectively increased by $4.05 \%$ and $11.10 \%$ than W1 when the identical vermiculite laying way was Z2. The number and percentage of red leaves in Z2 were increased by $6.49 \%$ and $0.06 \%$ than $\mathrm{Z} 0$ when irrigation amount was $\mathrm{W} 2$, respectively. W2Z2 treatment saving $50 \%$ irrigation amounts when compared with the treatment of W1Z0, though a fall for the number (decreased by 12.77\%) and percentage (decreased by $9.44 \%$ ) of red leaves of poinsettia, the difference was not significant.

\subsection{Effect of different irrigation amounts and vermiculite treatments on evapotranspiration and transpiration of poinsettia}

The diurnal variation of evapotranspiration and transpiration of poinsettia showed in Fig 2. As showed in figures, diurnal change of evapotranspiration and transpiration of the flower increased over time, the maximum were all arrived at period of 14:00-16:00, and then gradually dropped. Daily evapotranspiration and transpiration in W1Z0 treatment were all lower than other treatments (P < $0.05)$.

Significant analysis results showed that effect was significant of different irrigation amounts and vermiculite treatments as well as their interaction on diurnal variation of evapotranspiration (Fig. 2a) and transpiration (Fig. 2b) of poinsettia $(\mathrm{P}<0.05)$. Data analysis showed that evident decrease could be obtained in treatment $\mathrm{W} 2$ than $\mathrm{W} 1$ when vermiculite laying mode was the same $(\mathrm{P}<0.05)$ (except for period from 8:00 to 10:00). The evapotranspiration of poinsettia at the period of 10:00-12:00, 12:00-14:00, 14:00-16:00, 16:00-18:00 obviously decreased by 24.56\%, 17.91\%, 27.72\%, 23.87\% in W2 than W1 when vermiculite laying way was Z2, and transpiration decreased by $33.33 \%, 6.67 \%$, 7.39\%, 24.33\% in the same period, respectively. The transpiration of poinsettia at the period of 10:00-12:00, 12:00-14:00, 14:00-16:00, 16:00-18:00 significantly decreased by $26.70 \%, 35.29 \%$, 28.05\%, 38.65\% and 38.92\%, 26.67\%, 24.06\%, 27.01\% in Z0 than Z1 and Z2 when irrigation amount was $\mathrm{W} 1$, respectively. 


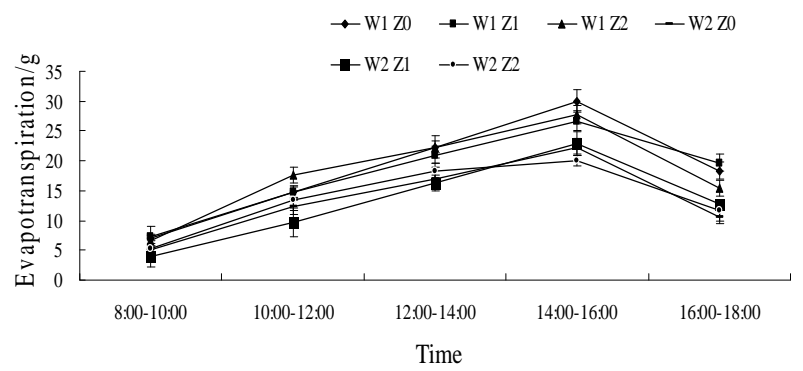

a

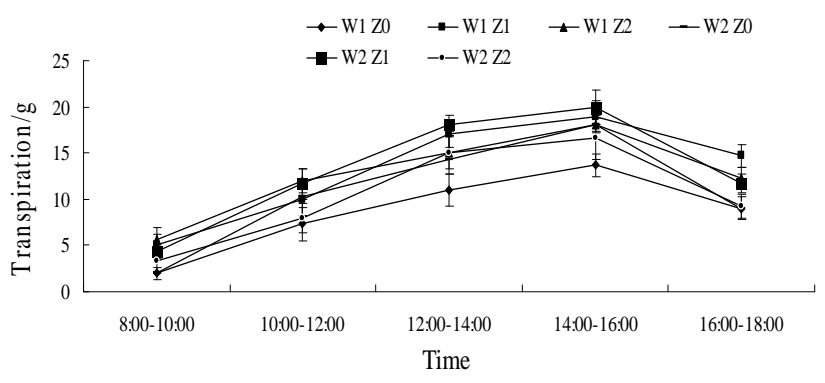

b

Fig.2 Effects of different treatments on diurnal transpiration and evapotranspiration of Poinsettia.

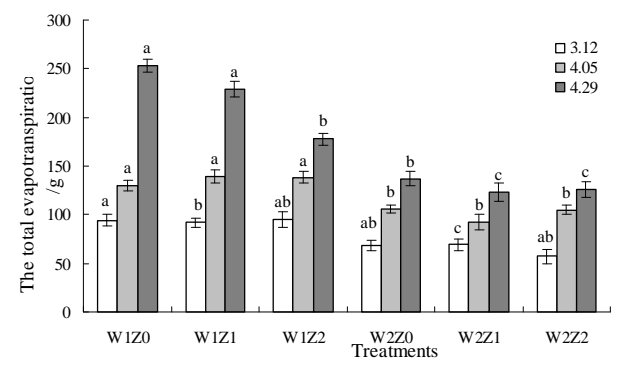

$\mathrm{a}$

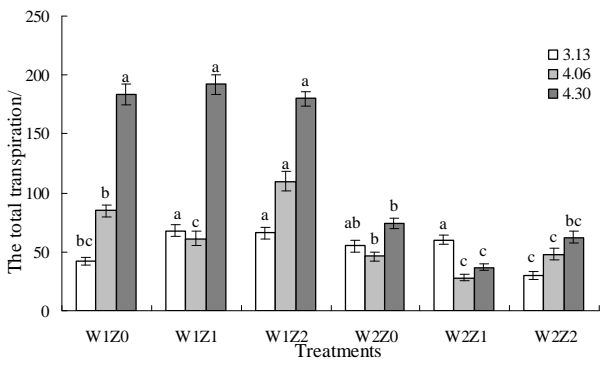

$\mathrm{b}$

Fig.3 Effects of different treatments on daily transpiration and evapotranspiration of Poinsettia.

Periodic change of evapotranspiration (Fig.3a)and transpiration (Fig.3b) of poinsettia under different treatments on March 12, April 5, April 29 for the former and March 13, April 6, April 30 for the latter showed in Fig. 3. Overall, the treatment of W2 could reduce the evapotranspiration and transpiration of poinsettia as compared with W1. Significant analysis results showed that, vermiculite laying methods (Z0, Z1, Z2) had no significant effect on poinsettia evapotranspiration $(\mathrm{P}>0.05)$, while the effect of irrigation amounts (W1 and W2) on evapotranspiration of poinsettia came to significant level $(\mathrm{P}<0.05)$, the influence was significant of irrigation amounts and vermiculite treatments as well as their interaction on transpiration of poinsettia $(\mathrm{P}<0.05)$.

Data analysis showed that, the evapotranspiration of poinsettia in W2 evidently decreased by 32.74\% than W1 under the treatment of Z2 (Fig. 3a) on April 29, and the transpiration of poinsettia in W2 significantly decreased by 73.98\% than W1 under the treatment of Z2 (Fig. 3b) on April 30. The transpiration of poinsettia in Z1 treatment obviously decreased by $49.11 \%, 32.94 \%$ than Z0 and Z1 on April 30 when irrigation amount was W2, respectively.

2.3 Effect of different irrigation amounts and vermiculite laying modes on the mass of dry matters and irrigation water use efficiency of poinsettia

Table 1 Effects of different treatments on dry matter (DM) and WUE ${ }_{I}$ of Poinsettia.

\begin{tabular}{lllllll}
\hline Treatments & $\mathrm{DM}_{\text {root }} / \mathrm{g}$ & $\mathrm{DM}_{\text {stem }} / \mathrm{g}$ & $\mathrm{DM}_{\text {red leaves }} / \mathrm{g}$ & $\mathrm{DM}_{\text {green leaves }} / \mathrm{g}$ & $\mathrm{DM}_{\text {whole }} / \mathrm{g}$ & $\mathrm{WUE}_{\mathrm{I}}\left(\mathrm{g} \cdot \mathrm{L}^{-1}\right)$ \\
\hline W1Z0 & $4.78 \pm 0.07 \mathrm{~b}$ & $7.28 \pm 1.09 \mathrm{~b}$ & $4.26 \pm 0.35 \mathrm{a}$ & $7.58 \pm 0.43 \mathrm{~b}$ & $23.89 \pm 1.13 \mathrm{~b}$ & $1.99 \pm 0.09 \mathrm{c}$ \\
$\mathrm{W} 1 Z 1$ & $6.03 \pm 1.32 \mathrm{a}$ & $9.40 \pm 0.46 \mathrm{a}$ & $3.01 \pm 0.31 \mathrm{~b}$ & $7.52 \pm 0.43 \mathrm{~b}$ & $25.92 \pm 2.20 \mathrm{a}$ & $2.16 \pm 0.18 \mathrm{bc}$ \\
$\mathrm{W} 1 Z 2$ & $4.95 \pm 0.32 \mathrm{~b}$ & $9.44 \pm 0.63 \mathrm{a}$ & $4.26 \pm 0.35 \mathrm{a}$ & $9.69 \pm 1.65 \mathrm{a}$ & $27.27 \pm 1.12 \mathrm{a}$ & $2.27 \pm 0.09 \mathrm{~b}$ \\
$\mathrm{~W} 2 Z 0$ & $3.79 \pm 0.07 \mathrm{~b}$ & $8.34 \pm 0.26 \mathrm{ab}$ & $3.15 \pm 0.09 \mathrm{ab}$ & $5.23 \pm 0.28 \mathrm{c}$ & $20.51 \pm 0.17 \mathrm{c}$ & $3.42 \pm 0.03 \mathrm{a}$ \\
W2Z1 & $3.96 \pm 1.16 \mathrm{~b}$ & $8.15 \pm 1.64 \mathrm{ab}$ & $1.71 \pm 0.83 \mathrm{c}$ & $4.60 \pm 1.46 \mathrm{c}$ & $18.42 \pm 2.29 \mathrm{c}$ & $3.07 \pm 0.38 \mathrm{a}$ \\
W2Z2 & $3.74 \pm 0.67 \mathrm{~b}$ & $7.48 \pm 0.55 \mathrm{~b}$ & $3.36 \pm 0.99 \mathrm{ab}$ & $6.02 \pm 0.39 \mathrm{bc}$ & $20.60 \pm 1.30 \mathrm{c}$ & $3.43 \pm 0.21 \mathrm{a}$ \\
\hline
\end{tabular}

Note: The data in the table is average of three times determination results, column with different letters represent significant difference $(\mathrm{P}<0.05)$.

As showed in table 1 that the effect varied of different irrigation amounts and vermiculite laying methods on the mass of dry matters in each organ and irrigation water use efficiency of poinsettia. The irrigation water use efficiency in $\mathrm{W} 2$ was significantly uplifted by $71.86 \%, 42.13 \%, 51.10 \%$ (P < 0.05) than $\mathrm{W} 1$ when vermiculite laying modes were $\mathrm{Z} 0, \mathrm{Z1}, \mathrm{Z2}$, respectively. There was no significant difference in mass of dry matters in roots, stems, red leaves, green leaves, whole plants and irrigation water use efficiency between the treatment Z0 and Z2 when irrigation amount was W2, neither obvious influence occurred on mass of dry matter in roots and red leaves in $\mathrm{Z} 2$ treatments in 
comparison to Z0 when irrigation amount was W1, but evident uplift appeared in mass of dry matters in stems, green leaves, whole plants as well as irrigation water use efficiency. Significant difference existed in total dry mass and irrigation water use efficiency between W1Z0 and W2Z2 treatment though there was no well-marked difference in mass of dry matters in roots, stems, red and green leaves.

\section{Discussion}

\subsection{Effect of different irrigation amounts and vermiculite laying methods on transpiration and} evapotranspiration of poinsettia.

Evapotranspiration has important influence on crop growth and development[13]. This test found that, the diurnal variation of evapotranspiration and transpiration of poinsettia showed a single peak curve and maximum occurred at period of 14:00-16:00. The daily evapotranspiration of poinsettia were all higher in W1 treatments than W2, while the same trend could not observed for daily transpiration of the flower, possible reason could be referred to relation between transpiration and ambient temperature as well as the number of poinsettia itself, the more leaves, the greater of transpirstion when at a certain temperature. The transpiration and evapotranspiration on April 29, 30 in Fig. 3 were greater than value of the previous two, possible reason may attributed to irrigation treatment on April 29, thus leading to a larger transpiration and evapotranspiration.

\subsection{Effect of different irrigation amounts and vermiculite laying modes on leaf number, the mass of dry matters and irrigation water use efficiency.}

Poinsettia, an ornamental plant, was paid high attentions by researchers in China. This study showed that, the mass of poinsettia dry matters significantly increased in W1 treatments when compared with W2, the main reason can be referred that increment of irrigation amount was beneficial to develop and growth of all poinsettia organs, promoting the increasing of plants biomass. While irrigation water use efficiency in W1 treatment obviously decreased when compared with W2, which was consistent with Wang [14]. When vermiculite was laid on the surface of substrate (Z1), it would evidently decrease the number of red leaves of poinsettia, that is to say the number of red leaves respectively decreased by 49.07\%, 70.37\% in W1Z1, W2Z1 when compared with W1Z0, W2Z0, correspondingly. Thus indicated that would decrease the number of red leaves when laying vermiculite on the surface of substrate in potted poinsettia flower. No significant difference could be observed in number and percentage of red leaves of poinsettia when vermiculite was laid within the basin below. Irrigation water use efficiency enhanced by $14.07 \%$ in W1Z2 when compared with W1Z0, that's WUEI was significantly uplifted when the vermiculite was laid within the basin below.

\section{Conclusion}

Effect was not significant of different irrigation amounts (W2, W1)on the number and percentage of red leaves of poinsettia when the vermiculite laying modes (Z0, Z1, Z2)were identical. Thus indicated that W2 treatments had no obvious effect on red leaves of poinsettia, that is to say irrigation amounts exerted no significant effect on ornamental of poinsettia. Irrigation water use efficiency was significantly uplifted by $71.85 \%, 42.13 \%$ and $71.85 \%(\mathrm{P}<0.05)$ in W2 than W1 when vermiculite laying method was consistent, and diurnal transpiration lower in treatment of W2 than W1. W2 treatment enhanced irrigation water use efficiency, saving water resource on the premise of exerting no affection on appreciation of poinsettia.

Evapotranspiration of poinsettia increased when vermiculite laying mode was Z1, the possible reason could be referred to the action that vermiculite slowed down the infiltration of water from the up to bottom in the flowerpot and caused extra moisture evaporation loss, thus leading to decrease of irrigation water use efficiency. The true reason why this phenomenon occurring still need to further explore in the later experiment, the best combination of irrigation and vermiculite which was beneficial to enhance appreciation of poinsettia was W2Z2 under the condition of trial. 


\section{Acknowledgements}

This research was supported by the National Natural Science Foundation of China (No.51009073,51379004,51109102) and the Applied Basic Research Programs of Science and Technology Commission Foundation of Yunnan Province (No. 2013FB024)

\section{References}

[1] Li Yang-hui, Xie Xiang-jian, Zhong Guo-jun, et al. Technical specification for poinsettia production[J]. Guangdong Agricultural Science, 2005, (4) : 93-96.In Chinese.

[2] Sun Xiang-Li, Zhang Qi-xiang. Effects of Watering Frequency and Fertilizer Amount on the Quality of Potted Euphorbia pulcherrima[J]. Acta Agriculturae Boreali-Sinica, 2010, 25 (Supplement) : 204.

[3] Liu B, Hein R D. Modeling poinsettia vegetative groAth and development: the response to the ratio of radiant to thermal energy[J]. Acta Horiculturae, 1998, 456: 133-142.

[4] Snipen L G, Moe R, Streng J. Influence of potential groAth factors in predicting time to floAering in poinsettia (Euphorbia pulcherrima)[J]. Scientia Horticultura, 1999, 81 (3) : 345-359.

[5] Kirsten R S, Niels E A. Effects of light and nitrogen supply on the allocation of dry matter and calcium in poinsettia(Poinsettia. ex KlotBsch)[J]. The Journal of Horticultural Science \& Biotechnology, 2000, 75(3) : 251-258.

[6] Xu Guo-bin, Luo Wei-hong, Chen Fa-di, et al. Effects of different pruning methods on the quality of potted Euphorbia pulcherrima[J]. Journal of Nanjing Agricultural University, 2006, 29 (1) : 23.In Chinese.

[7] Sun Zhao-fa, Han Ming-san, Zhai Xiao-ling. et al. Effect of Number of Short-day on Flowering and Visual Quality of Poinsettia [J]. Acta Horticulturae Sinica, 2006, 33 (3) : 583—586.

[8] Wei Cheng-Xiang, WANG Qing-Wu, Li Wen-Jin, et al. Tissue Culture and Rapid Propagation of Dwarf Type Euphorbia pulcherrima[J]. Plant Physiology Communications, 2000, 36 (3) : $234-235$.

[9] Wu Qiu-fang, Ma Rui-xia, Wang Jing-shun. Study on the Occurrence Regulation and Control of Bemisia tabaci in Anyang Region[J]. Hubei Agricultural Sciences, 2008, 47 (3) : 303-304.In Chinese.

[10]Wu Qiu-fang, Ma Rui-xia, Wang Jing-shun. Study on the Occurrence Regulation and Control of Bemisia tabaci in Anyang Region[J]. Hubei Agricultural Sciences, 2008, 47 (3) : 303—304.In Chinese.

[11]Jiang Ming-yan, Pan Yuan-zhi. Effects of Light Quality on the Photosynthetic Characteristics and Growth of poinsettia[J]. Acta Horticulturae Sinica, 2006, 33 (2) : 338-343.

[12]Feng L i-guo, Yu Ju, Tao Jun, et al. Effect s of high temperature stress on photosynthesis and chlorophyll fluorescence of Euphorbia pulcherrima[J]. Journal of Yangzhou University (Agricultural and Life Science Edit ion), 2009, 3(3) : 71-74.In Chinese.

[13]Liu Ya-ni, Wu Jian-jun, Xia Hong, et al. Summary of Two-layer Models on Estimating Evapotranspiration Using Quatitative Parameters Derived from Remote Sensing[J]. Arid Land Geography, 2005, 28 (1) : 65-69.

[14]Wang Shu-fen, Zhang Xi-ying, Pei Dong. Impacts of different water supplied conditions on root distribution, yield and water utilization efficiency of winter wheat[J]. Transactions of the CSAE, 2006, 22 (2) : 27-32. 